\title{
Effect of EMS and SA on Pollen sterility in Vigna radiata(L.) Wilczek (Mung bean).
}

\author{
M. P. Kulthe \\ Department of Botany Milind College of Science, Nagsenvana, Aurangabad, Maharashtra, India. \\ Corresponding Author: mpkulthe@gmail.com
}

\section{Manuscript Details}

Manuscript Submitted : 03/09/2019

Manuscript Revised : :13/09/2019

Manuscript Accepted : 15/09/2019

Manuscript Published : 15/09/2019

\section{$\underline{\text { Available On }}$}

https://plantaescientia.website/ojs

\section{Cite This Article As}

Kulthe M P, (2019). Effect of EMS and SA on pollen sterility in Vigna radiata (L.) Wilczek (Mung bean). Pla. Sci. 2019; Vol. 02 Iss. 03:4041. DOI: https://doi.org/10.32439/ps.v2i3.40-41

\section{Copyright}

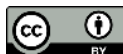

(c) The Author (s). 2019. Open Access This article is distributed under the terms of the Creative Commons Attribution 4.0 International License http://creativecommons.org/licenses/by/4.0/

\section{$\underline{\text { Indexed In }}$}

Crossref, Index Copernicus International (ICI), Directory of Research Journal Indexing (DRJI), Scientific Indexing Services (SIS),

\section{CiteFactor}

\section{ABSTRACT}

The seeds of Vigna radiata (L.) Wilczek (Mung bean) variety was treated with the chemical mutagens viz EMS and SA to study pollen sterility. EMS with $0.05 \%, 0.10 \%, 0.15 \%$ concentrations and Sodium azide with $0.01 \%, 0.02 \%, 0.03 \%$ concentrations. Pollen sterility is directly proportional to concentrations ie. increase in concentrations increases pollen sterility.

Keywords: Effect of EMS \& SA., Vigna radiata (L.) Wilczek, Pollen Sterility, Mung bean.

\section{INTRODUCTION}

Mutation breeding is one of the most useful technique to induce mutations in plant system. It used to introduce novel character in plant. Mutagen used are of two types those are physical and chemical mutagens. Mutagen before using LD 50 is determined to check the effect of mutagen on organism. Different criterion used to study the efficiency and effectiveness of it. Mutagenic efficiency is scored by observing genetic damage as mutagenic effectiveness is response of genotype to the different doses of mutagen ( Mohd Rafiq Wani et.al., 2011) efficiency is depend on doses of mutagens administered in seeds. Mung bean is one of the most consumed protein source in the world. 


\section{MATERIALS AND METHODS}

Healthy and dry seeds of variety Unnati were selected for mutagenic treatments. These mutagenic treatments which were given to the seeds by using chemical mutagens administered at room temperature of $25+-2$ C. Seeds were soaked in distilled water for six hours. These presoaked seeds were then treated with mutagen solutions for twelve hours and then treated seeds were washed thoroughly with distilled water. These seeds were soaked in distilled water after mutagenic treatments. To facilitate uniform absorption volume of chemical mutagenic solutions used was five times more than that of seeds which makes them fully submerged in it. Seeds soaked in 12 hours in distilled water were used as control. For mutagenic treatments different concentrations were prepared. In SA they were $0.01 \%, 0.02 \%$, and $0.03 \%$ and in EMS $0.05 \%, 0.10 \%$, and $0.15 \%$. 400 seeds were used for each treatment with three replications. Randomized block design was used to sow seeds.

Pollen sterility was studied in twenty (20) randomly selected plants of each mutagenic treatment. From freshly dehisced anthers pollen grains were collected and stained with acetocarmine. Pollen grains which stained fully were counted as fertile while the shrivelled ones and partially stained pollens were considered as sterile.

\section{RESULTS AND DISCUSSION}

The pollen sterility in control recorded was $4.7 \%$. The highest value of pollen sterility was observed in $11.52 \%$ in $0.15 \%$, lowest in $0.05 \%$ and $9.86 \%$ in $0.10 \%$ concentrations of EMS. In Sodium azide it was recorded that lowest value was $5.22 \%$ in $0.01 \%$, highest value 8.62 in $0.03 \%$. In $0.02 \%$ it was observed as $7.81 \%$.Mutation breeding introduces more genetic variability in the plants like mung bean which contains limited genetic variability (Auti, 2012). The most common factor of mutagen induced sterility is chromosomal aberrations and hence the common form of sterility is the occurrence of nonfunctional gametes (S. Ignacimuthu $\&$ C. R. Babu 1989). Pollen sterility is a way to study the efficiency of mutagens. Pollen sterility increase when concentration of mutagen increased. It was recorded by S Ignacimuthu and C. R. Babu (1989) in different species of Vigna or Vigna sublobata, Vigna radiata and Vigna mungo. They observed trends that increased pollen sterility was dose-dependent increase which is also related to increase in the meiotic chromosomal aberrations. Such relationship was proved highly significant. Kashid and Kulthe (2011) in Okra varieties Arka Anamika and Parbhani Kranti recorded that when used chemical mutagens pollen sterility increased as concentration increased. Pollen sterility is an index of disturbances in reproductive machinery increased as dose of Gamma rays increases in Chilly (Rao et al 1991) as well as in Okra (Nandapuri et al 1971). Kothekar \& Dnyansagar (1985), reported the increase in pollen sterility by ionizing radiations. Pollen sterility is induced by chemical mutagenic treatment also has been recorded by Gaul et al (1966), Kothekar (1978), Deshpande (1980) and Hakande (1992) in different plant systems.

\section{CONCLUSION}

From above results and discussion it is concluded that EMS is more effective mutagen than Sodium azide. As the concentration of Mutagenic treatment increased pollen sterility increases.

Table 1: Pollen sterility in \% induced by EMS and SA

\begin{tabular}{|c|c|c|}
\hline Mutagen & Concentrations & Pollen sterility in $\%$ \\
\hline Control & - & $04.70 \%$ \\
\hline \multirow{3}{*}{ EMS } & $0.05 \%$ & $06.61 \%$ \\
& $0.10 \%$ & $09.86 \%$ \\
\hline \multirow{2}{*}{ SA } & $0.15 \%$ & $11.52 \%$ \\
& $0.01 \%$ & $05.22 \%$ \\
\hline & $0.02 \%$ & $07.81 \%$ \\
\hline
\end{tabular}

\section{ACKNOWLEDGEMENTS}

Author is thankful to Principal, Milind College of Science, Aurangabad, to making available facilities for present work.

\section{REFERENCES}

Auti Sanjay G, (2012). Bioremediation, Biodiversity and Bioavailability Global Science Book, 6 (special issue I) pp 27-39.

Deshpande, N. M., (1980). The effect of Gamma rays and chemical mutations in Momordica charantia L. Ph.D. Thesis University of Nagpur.

Gaul H. and Aastveit K., (1966). Induced variability of culm length in different genotypes of hexaploid wheat following $\mathrm{x}$-irradiation and EMS treatment contact agric., 11-12:263-276

Hakande T.P. (1992). Cytogenetical studies in Psophocarpus tetragonolobus (L.) DC., Ph.D. thesis Marathwada University, Aurangabad India

Ignacimuthu, S. and C. R. Babu (1989). Induced chromosome abnormality and pollen sterility in wild and cultivated Urd and Mung beans. Cytologia 54:159-167.

Kashid N. G. and Kulthe M.P. (2011). Effect of physical and chemical mutagen on pollen sterility in Okra, Interlink research analysis,vol.II, 14,Jan.to Jun.,2011

Kothekar V.S. (1978). Mutational studies in Solanum nigrum L. PhD thesis University of Nagpur.

Kothekar V.S. and Dnyansagar (1985). Polyploidy and sensitivity to radiations in Solanum nigrum L. J genet. 20: 79-88.

Mohd Rafiq Wani, Samiullah Khan and Mohammad Imran (2011). Front. Agric. China 2011, 5(4):514-518

Nandapuri K. S., Sandhu K.S. and Randhava K. S. (1971). Effect of irradiation on variability of Okra (Abelmoschus esculentus (L) Moench) J. Res.P.A.U.8:183-188

Rao Ramana, Y. V. Rao, M. V. B Ravindra Babu, V. Ramakumari, P. V. and Subramanyam D. (1991). Efficiency and effectiveness of physical and chemical mutations in M2 generations of Chile Nuclear Agric Biol. 20(4):255-259.

(C) 2019| Published by Plantae Scientia 